\title{
Variable effects of larval size on post-metamorphic performance in the field
}

\author{
Dustin J. Marshall ${ }^{1,2, *}$, Michael J. Keough ${ }^{1}$ \\ ${ }^{1}$ Department of Zoology, The University of Melbourne, Victoria 3010, Australia \\ ${ }^{2}$ Present address: School of Biological, Environmental \& Earth Sciences, University of New South Wales, \\ New South Wales 2052, Australia
}

\begin{abstract}
Larval quality may be capable of explaining much of the variation in the recruitment and subsequent population dynamics of benthic marine invertebrates. Whilst the effects of larval nutritional condition on adult performance have received the most attention, recent work has shown that larval size may also be an important and ubiquitous source of variation in larval quality. We examined the effects of variation in larval size on the post-metamorphic survival and growth of Watersipora subtorquata in 2 very different habitats-experimental substrata and pier pilings. We found strong effects of larval size on colony performance, although these varied among experiments. For colonies on experimental substrata, larval size positively affected adult survival and, initially, growth. However, after $3 \mathrm{wk}$ in the field, there was no relationship between larval size and colony size, possibly because colonies were completely surrounded by newly settled organisms. Larval size also positively affected post-metamorphic growth of colonies on pier pilings, but, surprisingly, colonies that came from larger larvae had lower survival than colonies from smaller larvae. Overall, variation in larval size will strongly affect the recruitment and subsequent performance of adults in this species, although this may vary among different habitats. This study highlights the importance of examining the effects of larval quality on adult performance in as realistic conditions as possible, because of the strong interaction between larval size effects and the environment.
\end{abstract}

KEY WORDS: Bryozoan · Carry-over effects · Egg size

\section{INTRODUCTION}

One of the principal factors determining the distribution and abundance of benthic marine invertebrates is the recruitment of new individuals into populations (Underwood \& Fairweather 1989, Underwood \& Keough 2001). The recruitment of marine invertebrates can be remarkably variable and, for many years, marine ecologists have attempted to identify and understand the sources of this variability (Hunt \& Scheibling 1997). Much of the work to date has focused on how variation in the quantity of larvae reaching adult populations affects recruitment and subsequent population dynamics, but there is a growing recognition that the quality of larvae may also be important (Hunt
\& Scheibling 1997). There appear to be strong links between the quality of settling larvae and their probability of recruiting into the adult population. Variation in physiological condition of larvae has been shown to affect important determinants of fitness, including survival, growth and reproduction of adults (Pechenik et al. 1998, Pechenik 1999). These 'carry-over' effects have been documented in a wide variety of phyla, spanning most larval developmental modes and in both solitary and colonial organisms.

Whilst the link between larval quality and adult performance is clear, this link is only ecologically relevant if there is significant, natural variation in the quality of settling larvae (Phillips \& Gaines 2002). The most commonly cited source of variation in larval quality is 
nutritional condition (Hunt \& Sheibling 1997, Pechenik et al. 1998, Pechenik 1999). The quality of larvae settling in nature can vary significantly within and among cohorts according to their nutritional history or length of metamorphic delay (Barnes 1953, Connell 1961, Pechenik 1990, Jarrett \& Pechenik 1997, Phillips \& Gaines 2002), and the consequences of this variation for adult growth have been studied for a range of organisms (Jarrett \& Pechenik 1997, Pechenik et al. 1998, Wendt 1998, Vaitilingon et al. 2001, Phillips 2002, Jarrett 2003, Marshall et al. 2003a). Another potential source of variation in larval quality is size, although the effects of larval size on adult performance have received relatively less attention (Moran \& Emlet 2001, Marshall \& Keough 2003a, Marshall et al. 2003b). This lack of attention is remarkable given the wide intraspecific variation in offspring size for a wide range of marine invertebrate taxa (George 1994, Jones et al. 1996, Marshall \& Keough 2003b,c). Because variation in larval size is so common, it has the potential to explain much of the currently unaccounted for variation in the recruitment success and subsequent performance of marine invertebrates (Hunt \& Scheibling 1997); however, more field tests are needed.

Offspring size has long been assumed to be positively correlated with offspring fitness and is central to life-history theory (e.g. Smith \& Fretwell 1974, Stearns 1992, Hendry et al. 2001), but field tests in the marine environment are rare (Moran \& Emlet 2001). There is some indirect evidence for increased offspring investment resulting in higher fitness in marine invertebrates. In the colonial ascidian Botryllus schlosseri, related settlers fuse, thereby becoming larger colonies which are known to have higher fitness (Grosberg \& Quinn 1986). Viewed from the perspective of the maternal colonies, the fusion of sibling settlers represents a form of increased per capita investment. This is an extreme example of the advantages of increasing maternal investment (i.e. doubling) but it does suggest that offspring size effects may be common in marine invertebrates. The effects of offspring size on offspring fitness appear to vary strongly under different environmental conditions, and so field tests should include as wide a range of conditions as possible in order to assess whether offspring size effects are widely relevant (Einum \& Fleming 1999, Moran \& Emlet 2001). Here, we examine the effects of variation in larval size on subsequent adult survival and growth in the field for the encrusting bryozoan Watersipora subtorquata. In one set of experiments, we transplanted metamorphosing colonies into the field on artificial settlement plates. Later, we repeated our experiments at the same site under more realistic conditions-on the pier pilings where $W$. subtorquata is commonly found.

\section{MATERIALS AND METHODS}

Field site and collection of larvae. All experiments and the collection of reproductively mature colonies were done at Breakwater Pier in Williamstown, Victoria, Australia, during March 2001 (settlement plate experiments) and July 2001 and March 2002 (pier piling experiments). The site is sheltered from the prevailing weather by a large rocky breakwater, and the sessile invertebrate community has been described by Keough \& Raimondi (1995). The water temperature for the experimental period was 18 to $21^{\circ} \mathrm{C}$ in March in both years and $12^{\circ} \mathrm{C}$ in July 2001. Reproductively mature colonies were collected from artificial settlement plates that had been placed in the field 2 mo earlier. To collect larvae, colonies were held in recirculating aquaria in constant darkness for $2 \mathrm{~d}$ before being exposed to bright light. Watersipora subtorquata colonies began spawning after about 30 min of exposure to light. The larvae were collected quickly with a pipette and each was offered a settlement surface within 20 min of release from the parent colony. We collected larvae from 10 colonies, taking care to select a range of larval sizes from each colony. The size range of larvae used in our experiments was 2.5-fold and pilot studies indicated that the size range of $W$. subtorquata settlers obtained from the laboratory was well within that of natural settlers at Williamstown (Marshall \& Keough 2003c).

Measurement of larvae and field deployment. Settlement plates: Ideally, to assess the effects of offspring size on post-metamorphic performance, we would have measured larval size directly. However, measuring larvae is time-consuming and we were concerned that delaying the metamorphosis of the larvae could affect post-metamorphic performance (e.g. Wendt 1998, Marshall et al. 2003a). Consequently, we allowed larvae to settle immediately after collection and measured the size of the subsequent settlers $12 \mathrm{~h}$ after settlement. Settler size is a good $\left(\mathrm{R}^{2}\right.$ $=0.78$ ) estimate of larval size in Watersipora subtorquata (Marshall \& Keough 2003c). We placed larvae on their own individual settlement plate in a small drop of seawater (see Marshall et al. 2003a). The settlement plates $(10 \times 10 \times 1 \mathrm{~cm})$ were made of grey PVC and had been roughened with sand paper to encourage settlement. Any larvae that failed to settle within $30 \mathrm{~min}$ were discarded. We then marked the place of each settled larva by placing a small dot next to the metamorphosing individual with a pencil. The settlement plates were then placed into recirculating aquaria at $15^{\circ} \mathrm{C}$ for $12 \mathrm{~h}$. Approximately $12 \mathrm{~h}$ after settlement, we briefly videotaped each settler, digitised the footage and measured each settler using SigmaScan (Jandel Scientific Ver. 3; see Marshall et 
al. 2003b). The measurements were then calibrated against footage of a haemocytometer grid that had been videotaped with the same equipment. Once the settlers had been measured, the settlement plates were immersed in seawater and transported to the field site (approximately 20 min away) in insulated aquaria. The settlement plates were attached to large $(90 \times 90 \mathrm{~cm})$ Perspex backing plates with stainless steel bolts. Settlement plates were arranged so that their position on the backing plate was haphazard. The backing plates were then hung horizontally with the experimental plates facing down (to minimise the effects of light and sedimentation) at a depth of $\sim 2 \mathrm{~m}$ below mean low tide.

Pier pilings: For our experiments on pier pilings, we settled the larvae onto the ends of small Perspex plugs rather than settlement plates (see Fig. 1). One end of each plug was roughened to encourage settlement. A tight-fitting, clear plastic collar was placed around the roughened end so that it could hold $\sim 1 \mathrm{ml}$ of seawater.

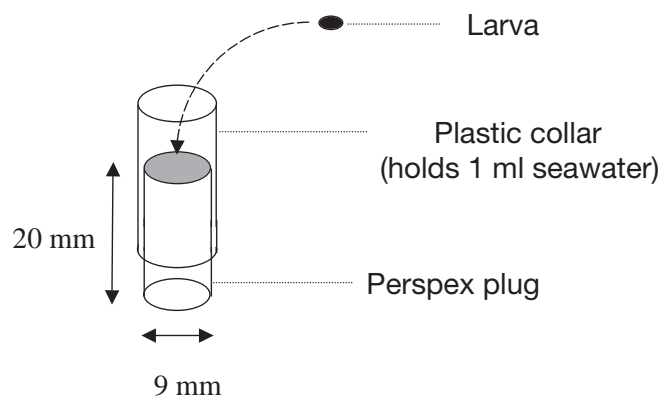

\section{Laboratory}

\section{Field}

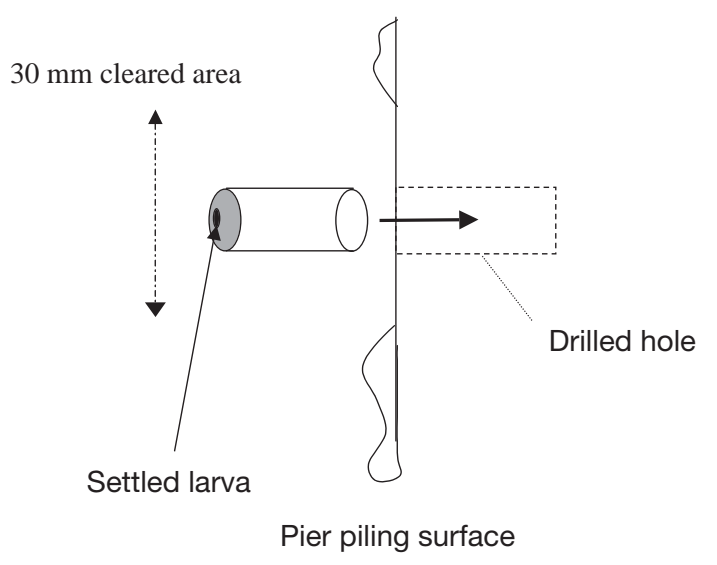

Fig. 1. Schematic of apparatus to deploy Watersipora subtorquata settlers onto pier pilings in the field at Williamstown, Australia
We allowed settlement to occur as described above and then sorted larvae into large $\left(>0.23 \mathrm{~mm}^{2}\right)$ and small $\left(<0.23 \mathrm{~mm}^{2}\right)$ size classes with an ocular micrometer. Approximately $12 \mathrm{~h}$ after settlement, the Perspex plugs (with settlers and plastic collars attached) were transported to the field immersed in seawater in insulated plastic aquaria. The plastic collars protected the settlers during transportation and no settlers were damaged or killed in the process of deploying them into the field.

One wk prior to placing the settled larvae into the field, small ( $\sim \mathrm{cm}$ diameter) holes had been handdrilled into the pier pilings at a depth of $2 \mathrm{~m}$ below the low water mark. At this depth Watersipora subtorquata is a common component of the fouling community in Williamstown (authors' pers. obs.). A small $(3 \mathrm{~cm}$ diameter) area around each hole was cleared of encrusting organisms. Once the settlers had been brought to the field, we used SCUBA to deploy the Perspex plugs. Underwater, we removed the plastic collars and carefully placed the Perspex plugs into the drilled holes so that the end of the plug (with settler attached) was flush with the pier piling surface (Fig. 1). Large and small settlers were distributed haphazardly across 8 pier pilings, with 6 to 12 settlers (approximately equal number of both size classes) placed on each. The Perspex plugs were a snug fit in the drilled holes and no adhesive was necessary to hold them in place.

Sampling. For Watersipora subtorquata on settlement plates, Run 1 ( $\mathrm{n}=30$ ) was deployed on March 3, 2001, and Run 2 ( $\mathrm{n}=21$ ) on March 18, 2001. Run 1 was in the field for $2 \mathrm{wk}$ and Run 2 for $3 \mathrm{wk}$. For both Runs, we assessed colony survival and growth after 2 wk in the field, and for Run 2, again after $3 \mathrm{wk}$ in the field. To measure colony survival and growth, we hauled the backing plates onto the pier and placed them face up in a shallow bath of seawater. We then determined the presence/absence of colonies and, for those colonies that were still present, we counted the number of zooids that had developed orifices. Each census took approximately 30 min, after which the backing plates were immediately redeployed.

For Watersipora subtorquata on pier pilings, Run 1 was deployed into the field on July 31, 2001 ( $\mathrm{n}=29$ ). Run 2 was deployed ( $\mathrm{n}=100$ ) on March 21, 2002; during this time 12 Perspex plugs fell out of the pilings and were disregarded from further analysis. We assessed colony survival and size after $3 \mathrm{wk}$ in the field by examining each settlement plug underwater with a magnifying glass and a torch whilst on SCUBA. Colony size was assessed as above.

Larval size and budding rate. We found that larger settlers had higher post-metamorphic growth than 
smaller settlers (see 'Results'). We hypothesised that this higher growth rate was due to a higher initial budding of new daughter zooids in larger settlers. To test this hypothesis, we collected reproductively mature colonies and spawned them in the laboratory as described above. We allowed the larvae to settle on Petri dishes and measured the settlers as described above and then measured the number of new zooids formed $5 \mathrm{~d}$ after settlement.

Data analysis. In all analyses, we first checked that the data satisfied the assumptions of each analysis. For the Watersipora subtorquata on settlement plates, we used logistic analysis of covariance (ANCOVA) to assess survival after $2 \mathrm{wk}$ in the field, where experimental run was a categorical, random factor and settler size was a covariate. We first tested for an interaction between run and settler size and, as this interaction was not significant $(\mathrm{p}=0.294)$, we ran a reduced model with the interaction term removed. We then used the equation produced from the logistic ANCOVA to generate survival probabilities for the size range of larvae in our study. To assess survival at the other time period ( $3 \mathrm{wk}$ ), we used logistic regression, where settler size was a continuous predictor variable. To examine the effect of settler size on subsequent colony size after $2 \mathrm{wk}$ in the field, we used ANCOVA, where settler size was a covariate and run was a categorical factor. We first tested for an interaction between settler size and run, and because this interaction was not significant $\left(F_{1,40}=0.03, \mathrm{p}=0.864\right)$, we ran a reduced model with the interaction term removed. For Run 2, we examined whether settler size affected colony size after 3 wk using linear regression.

To assess the survival of Watersipora subtorquata on pier pilings we used a paired $t$-test, where the proportionate survival of large and small settlers on each pier piling was the response variable, pooling across runs. We first tested whether there was any interaction between larval size and run, and as there was no significant interaction $(\mathrm{p}=0.489)$ and run was of no biological interest and explained little of the variation, it was omitted from further analysis (Quinn \& Keough 2002). To test the effects of settler size on subsequent $W$. subtorquata colony size on pier pilings, we again removed the non-significant run factor from the model and used ANOVA, where settler size was a fixed factor and pier piling was a random, blocking factor.

To assess the effect of larval size on initial ancestrulae (the first feeding zooid in the colony) budding rate, we used logistic regression, where settler size was a continuous predictor variable and budding (new daughter zooid formed or not) was a categorical response variable.

\section{RESULTS}

\section{Settlement plates}

For Watersipora subtorquata on settlement plates, the majority of mortality occurred in the first week after deployment in the field. Pooling across runs for $W$. subtorquata on settlement plates, $\sim 16 \%$ of all the juvenile colonies died in the first $2 \mathrm{wk}$. The mortality of juvenile colonies after $2 \mathrm{wk}$ in the field was size dependent for both runs (Table 1). Across the range of settler sizes ( 2.5-fold difference), the predicted survivorship ranged from $47 \%$ for the smallest settler and $98 \%$ for the largest (values back-calculated from logistic regression equation). Mortality remained size dependent for Run 2 after 3 wk in the field (Table 1).

Colony growth varied between experimental runs on settlement plates, but colony size after 2 wk remained strongly influenced by settler size in both runs (Table 2, Fig. 2). However, after 3 wk in the field, no effect of settler size on colony size could be detected in Run $2\left(R^{2}=0.001, p=0.904, n=14\right)$, but, interestingly, colony size after $3 \mathrm{wk}$ was still correlated with colony size after $2 \mathrm{wk}\left(\mathrm{R}^{2}=0.69, \mathrm{n}=14\right)$. After $3 \mathrm{wk}$ in the field, the growing edges of the colonies were almost completely surrounded by newly settled barnacle species and various serpulid worms.

\section{Pier pilings}

For Watersipora subtorquata on pier pilings, mortality was much higher than on settlement plates, with 56 to $45 \%$ (Runs 1 and 2, respectively) mortality in the first $3 \mathrm{wk}$ after settlement. Mortality was size dependent for $W$. subtorquata on pier pilings $(t=2.341$, $\mathrm{df}=$ 10, $\mathrm{p}=0.041$; Fig. 3). Colonies that came from smaller larvae were more likely to survive than colonies that

Table 1. Watersipora subtorquata. Logistic ANCOVA (at $2 \mathrm{wk}$ ) and regression ( $3 \mathrm{wk}$ ) of the effects of initial settler size on subsequent mortality of colonies on settlement plates after 2 and 3 wk in the field at Williamstown, Australia. Wald tests were used to test the significance of particular effects with degrees of freedom of 1 for both settler size and run effects. $\mathrm{p}$ values $<0.05$ shown in bold. For Run $1, \mathrm{n}=30$, for Run 2 , $\mathrm{n}=21$

\begin{tabular}{|lcccc|}
\hline Field duration & Parameter & Odds ratio & $\chi^{2}$ & $\mathrm{p}$ \\
\hline 2 wk & Size & 1.000 & 3.902 & $\mathbf{0 . 0 4 8}$ \\
(Runs 1 and 2) & Run & & 0.064 & 0.8 \\
& McFadden's $\rho^{2}$ & & & 0.183 \\
& & & & \\
3 wk & Size & 1.000 & 4.702 & $\mathbf{0 . 0 3 0}$ \\
(Run 2) & McFadden's $\rho^{2}$ & & & 0.250 \\
\hline
\end{tabular}


Table 2. Watersipora subtorquata. ANCOVA of effects of settler size on the growth of colonies on settlement plates after 2 wk in the field at Williamstown, Australia. Note the model is reduced after testing for heterogeneity of slopes

\begin{tabular}{|lrrrr|}
\hline Source of variation & df & \multicolumn{1}{c}{ MS } & \multicolumn{1}{c|}{$F$} & \multicolumn{1}{c|}{ p } \\
\hline Settler size & 1 & 57.6 & 7.5 & $\mathbf{0 . 0 0 9}$ \\
Run & 1 & 226.9 & 29.4 & $<\mathbf{0 . 0 0 1}$ \\
Residual & 41 & 7.7 & & \\
\hline
\end{tabular}

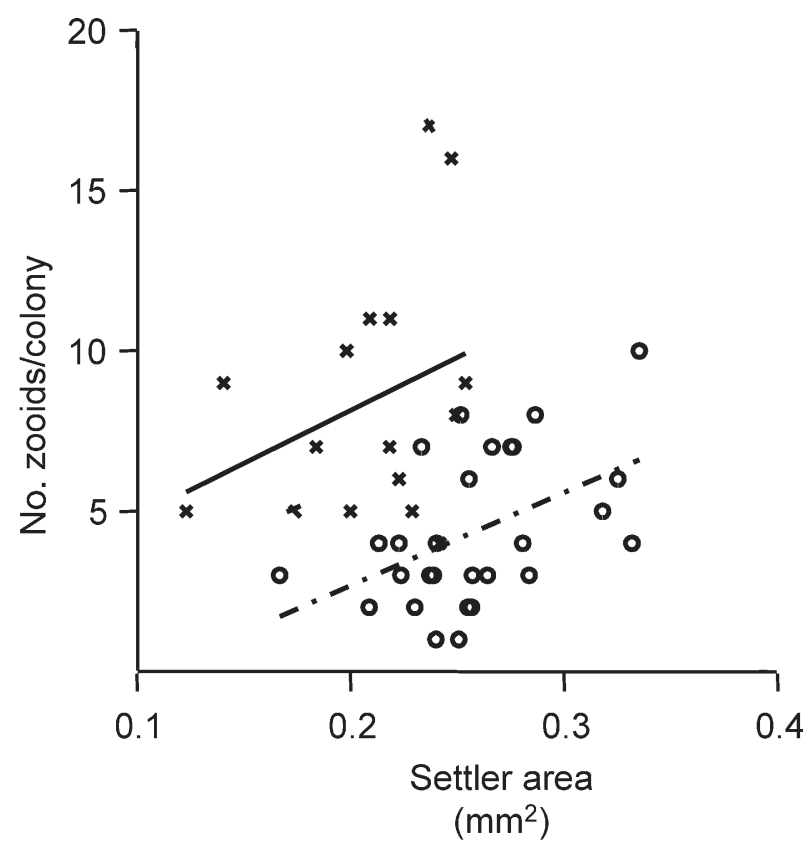

Fig. 2. Watersipora subtorquata. Effect of settler size on colony size after $2 \mathrm{wk}$ in the field at Williamstown Australia. Individual colonies from Run $1(\mathbf{0})$ and Run $2(\boldsymbol{x})$ are shown

came from larger larvae. For $W$. subtorquata on pier pilings, colony growth was much slower than on settlement plates. Nevertheless, colony size $3 \mathrm{wk}$ after settlement was still strongly affected by initial settler size in both runs (Table 3, Fig. 4). The settlement of solitary organisms onto the cleared area surrounding the experimental colonies appeared to be very low when compared to the amount of settlement typically found on settlement plates during the same period.

\section{Settler size and budding rate}

Larger settlers formed a new zooid more quickly than smaller settlers in the laboratory. Five days after settlement, larger settlers were more likely to have a second zooid than smaller settlers (Wald test: $\chi^{2}=$ 4.286, $\mathrm{p}=0.038, \mathrm{n}=29$ ).

\section{DISCUSSION}

Overall, larval size strongly affected post-metamorphic performance in Watersipora subtorquata, but these effects differed in both direction and type between the 2 sets of experiments. For our experiments on settlement plates, colonies that came from larger larvae survived better than colonies that came from smaller larvae. Larval size may affect early survival because larger settlers become larger colonies and may be more resistant to predation and other sources of mortality (Sebens 1982, 1987, Davis 1988). Alternatively, the period immediately after settlement may be an energetically critical stage and if larger larvae have greater energy resources, this may explain their higher survival rates. In a previous study, we found that initial settler size affected the early postsettlement survival of the solitary ascidian Ciona intestinalis (Marshall \& Keough 2003a). An interesting test of whether the effects of larval size on early postsettlement survival are driven by nutritional constraints would be to determine if supplemental food given to new settlers removes the effects of larval size.

After 2 wk in the field, colonies on settlement plates that came from larger larvae were larger than those that came from smaller larvae. This species joins a growing list of species for which initial growth rates

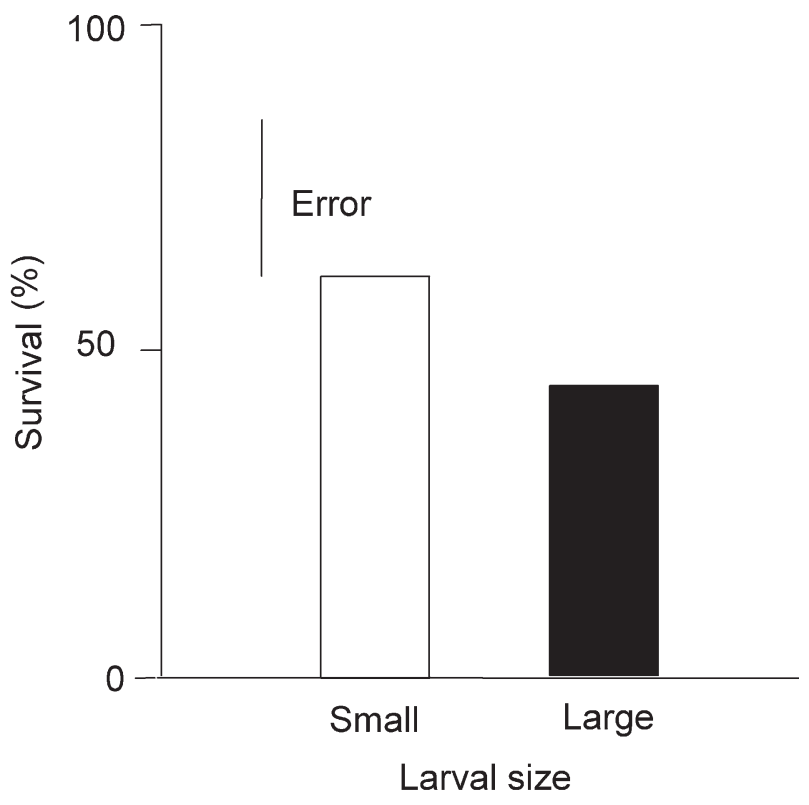

Fig. 3. Watersipora subtorquata. Effect of settler size on the percentage survival of large and small settlers on pier pilings at Williamstown, Australia. Open bar indicates small settlers, solid bar indicates large (see 'Materials and methods' for definition of sizes). The length of the error bar shown represents the standard deviation of the difference in survival of colonies within pier pilings 
Table 3. Watersipora subtorquata. ANOVA of the effect of settler size on the growth of colonies after $3 \mathrm{wk}$ in the field on pier pilings at Williamstown, Australia. $\mathrm{p}$ values $<0.05$ shown in bold. Model is reduced after removing the non-significant effect of run

\begin{tabular}{|lrrrr|}
\hline Source of variation & df & MS & \multicolumn{1}{c|}{$F$} & $\mathrm{p}$ \\
\hline Size & 1 & \multicolumn{1}{c}{49.72} & 16.211 & $\mathbf{0 . 0 0 5}$ \\
Piling & 7 & 13.523 & 4.532 & $\mathbf{0 . 0 0 1}$ \\
Piling $\times$ Size & 7 & 3.067 & 1.028 & 0.424 \\
Error & 48 & 2.984 & & \\
\hline
\end{tabular}

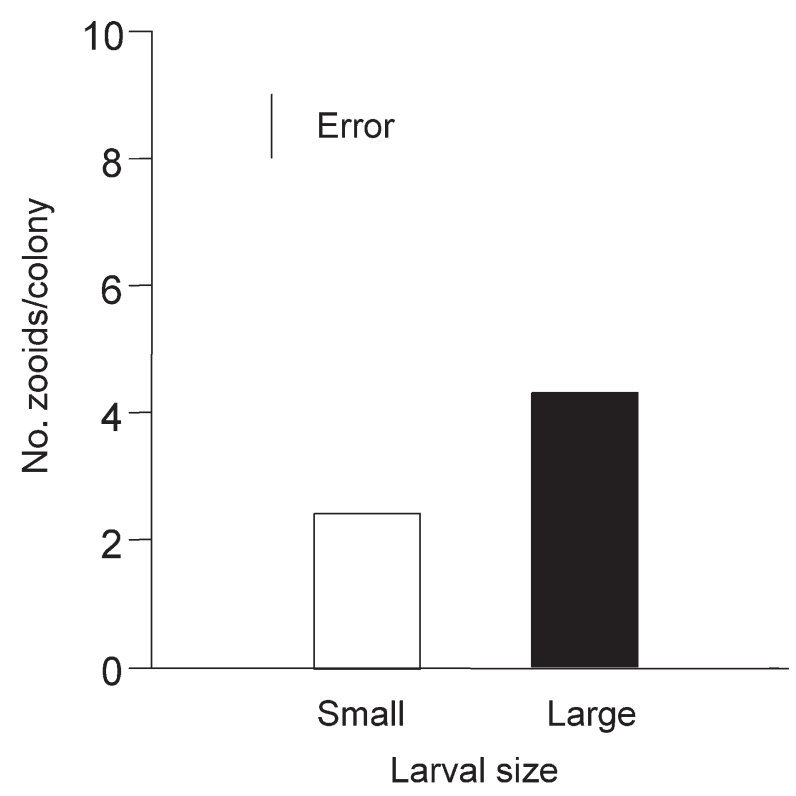

Fig. 4. Watersipora subtorquata. Effect of settler size on the size of colonies on pier pilings (Run 1) after $3 \mathrm{wk}$ in the field at Williamstown, Australia. Open bar indicates small settlers, solid bar indicates large (see 'Materials and methods' for definition of sizes). The length of the error bar represents the square root of the mean square for the interaction between piling and settler size, used to test the effect of size

are affected by larval size (Moran \& Emlet 2001, Phillips 2002, Marshall et al. 2003b). Larger Watersipora subtorquata settlers bud into new daughter zooids sooner than smaller settlers, and this is probably because larger settlers have greater nutritional reserves. The daughter zooids begin to form before the ancestrulae have fully developed their lophophores (feeding structures) and begun to feed. Consequently, the initial development of the daughter zooids may be entirely due to endogenous reserves (i.e. larval size). This initial difference in budding rate may explain why larval size affects initial colony growth rates and size after 2 wk. Wendt (1996) and Marshall et al. (2003a) found that colonies from larvae that had their nutritional reserves depleted by extended swimming produced smaller feeding structures. It appears that there is a range of mechanisms by which larval quality can affect the initial growth of colonial marine invertebrates.

After $3 \mathrm{wk}$ in the field, the experimental colonies on settlement plates were completely surrounded by other settled organisms (mainly serpulid polychaetes and barnacles) and we could no longer detect an effect of larval size on colony size. Watersipora subtorquata is a poor competitor (Barnby 1999) and it seemed that the growth of colonies was extremely limited by the settlement of other organisms, thereby obscuring any effect of larval size. Previously, we found that the effects of larval quality on colony growth were not persistent in another poor competitor, the colonial ascidian Diplosoma listerianum (Marshall et al. 2003a). Larval size affected initial growth in D. listerianum, but after $3 \mathrm{wk}$ in the field, colonies had begun to fragment and we could no longer detect an effect of larval size (Marshall et al. 2003a). In contrast, experiments on the arborescent bryozoan Bugula neritina showed persistent effects of larval size on colony growth for up to $6 \mathrm{wk}$ in the field (Marshall et al. 2003b). The effects of larval size may have been more persistent in $B$. neritina because of its growth form; $B$. neritina colonies can continue to grow upwards away from the substratum whilst in the presence of high densities of other competitors (Marshall et al. 2003b). Interestingly, for W. subtorquata on pier pilings (where the settlement of other organisms was very low), the effects of larval size on colony size persisted for $3 \mathrm{wk}$. It may be that the effects of larval size on growth may be more persistent when growth is not constrained by competition for space and, therefore, these effects may be more persistent in solitary, mobile organisms (e.g. Moran \& Emlet 2001).

The effects of larval size on the growth rates of colonies on pier pilings were similar in some respects to our results for those on settlement plates-colonies that came from larger larvae had higher growth rates than those that came from smaller larvae. However, colony growth rates on pier pilings were generally lower than those on settlement plates and, surprisingly, those from larger larvae had lower survival than those from smaller larvae. This contrasts with a number of other studies for marine organisms, where juveniles and adults that come from larger larvae generally have higher survivorship than those from smaller larvae (Moran \& Emlet 2001, Marshall \& Keough 2003a, Marshall et al. 2003b). The negative effects of increased larval size for colonies on pier pilings could be due to a range of factors. For example, larger settlers may be more attractive prey items to micropreda- 
tors (e.g. Osman \& Whitlatch 1995). If so, then previous studies on offspring size effects on settlement plates (that do not have the full range of predators) may have overestimated the positive benefits of larval size for adult performance (e.g. Marshall \& Keough 2003a, Marshall et al. 2003b). Alternatively, the different experimental period or substrates could also be responsible for the differential effects of larval size between the 2 sets of experiments. Regardless of the mechanism behind the negative correlation between larval size and colony survival, it is clear that offspring size and fitness are not always positively related in Watersipora subtorquata. This is a surprising result; few theoretical or empirical studies have demonstrated that larger offspring have lower fitness (but see Kaplan 1992, Hendry et al. 2001 for exceptions).

There is a growing body of literature on the effects of variation in larval quality on post-metamorphic performance (reviewed in Pechenik et al. 1998, Marshall et al. 2003a). This study highlights the importance of examining such carry-over effects in as realistic an environment as possible because, clearly, these effects are strongly dependent on local environmental conditions. Consequently, it may be inappropriate to use laboratory studies (e.g. Pechenik et al. 1996, Gebauer et al. 1999, Vaitilingon et al. 2001), where organisms are insulated from a range of mortality sources and pressures, to infer the importance of larval quality effects in the field. The use of small plugs to transplant newly metamorphosed individuals into the field appears to be an effective technique for exposing individuals to the widest possible range of environmental pressures.

It is important to note that throughout this study we have assumed that larval size is equivalent to larval energy content, an assumption that does not always hold in marine invertebrates (McEdward \& Coulter 1987). The positive effects of larval size on initial survival and growth in the absence of competitors (our experiments on settlement plates) suggest that larger larvae do have more energy reserves, but there are instances where this may not be the case. For example, delaying the metamorphosis of larger larvae may deplete their energy reserves so that they are energetically the same 'size' as smaller larvae (Wendt 2000). More tests are needed to examine how increased duration of larval swimming and larval size interact to affect post-metamorphic performance and compare their relative effects. Previously, we have shown that larger Watersipora subtorquata larvae are choosier with respect to settlement surfaces, and they swim for longer than smaller larvae (Marshall \& Keough 2003c). Smaller larvae have fewer energy resources to spare and have higher energy costs relative to their size (Wendt 2000). Therefore, we predict that the negative effects of increased larval swimming would be more detrimental for smaller larvae than larger larvae, but this remains to be tested.

Larval size affected the subsequent survival of Watersipora subtorquata colonies in both habitats in this study, although the direction of effects varied. We suggest that larval size will strongly affect the relationship between the abundance of settlers and the abundance of recruits: when larval size is more variable, the relationship between settlers and recruits will be weak and vice versa. Thus larval size will have a strong influence on the relative applicability of supply-side ecology in this species (Hunt \& Scheibling 1997, Underwood \& Keough 2001).

Acknowledgements. We thank M. Byrne, R. Emlet, C. Peterson and 2 anonymous reviewers for comments that greatly improved this manuscript. Thanks to P. Addison, S. Hart and D. Semmens for crucial assistance in the field. D.J.M. was supported by a Melbourne Research Scholarship and a ViceChancellors Fellowship (University of New South Wales) during the preparation of this manuscript.

\section{LITERATURE CITED}

Barnby VJ (1999) Post-settlement factors regulating the distribution of the encrusting bryozoan Watersipora subtorquata. Hons thesis, University of Melbourne

Barnes H (1953) Size variations in the cyprids of some common barnacles. J Mar Biol Assoc UK 32:297-304

Connell JH (1961) Effects of competition, predation by Thais lapillus, and other factors on natural populations of the barnacle Balanus balanoides. Ecol Monogr 31:61-104

Davis AR (1988) Colony regeneration following damage and size-dependent mortality on the Australian ascidian Podoclavella moluccensis Sluiter. J Exp Mar Biol Ecol 123: 269-285

Einum S, Fleming IA (1999) Maternal effects of egg size in brown trout (Salmo trutta): norms of reaction to environmental quality. Proc R Soc Lond B 266:2095-2100

Gebauer P, Paschke K, Anger K (1999) Costs of delayed metamorphosis: reduced growth and survival in early juveniles of an estuarine grapsid crab, Chasmagnathus granulata. J Exp Mar Biol Ecol 238:271-281

George SB (1994) Population differences in maternal size and offspring quality for Leptasterias epichlora (Brandt) (Echinodermata: Asteroidea). J Exp Mar Biol Ecol 175:121-131

Grosberg RK, Quinn JF (1986) The genetic control and consequences of kin recognition by the larvae of a colonial marine invertebrate. Nature 322:456-459

Hendry AP, Day T, Cooper AB (2001) Optimal size and number of propagules: allowance for discrete stages and effects of maternal size on reproductive output and offspring fitness. Am Nat 157:387-407

Hunt HL, Scheibling RE (1997) Role of early post-settlement mortality in recruitment of benthic marine invertebrates. Mar Ecol Prog Ser 155:269-301

Jarrett JN (2003) Seasonal variation in larval condition and postsettlement performance of the barnacle Semibalanus balanoides. Ecology 84:384-390

Jarrett JN, Pechenik JA (1997) Temporal variation in cyprid quality and juvenile growth capacity for an intertidal barnacle. Ecology 78:1262-1265 
Jones HL, Todd CD, Lambert WJ (1996) Intraspecific variation in embryonic and larval traits of the dorid nudibranch mollusc Aldaria proxima (Alder and Hancock) around the northern coasts of the British Isles. J Exp Mar Biol Ecol 202:29-47

Kaplan RH (1992) Greater maternal investment can decrease offspring survival in the frog Bombina orientalis. Ecology 73:280-288

Keough MJ, Raimondi PT (1995) Responses of settling invertebrate larvae to bioorganic films: effects of different types of films. J Exp Mar Biol Ecol 185:235-253

Marshall DJ, Keough MJ (2003a) Effects of settler size and density on early post-settlement survival of Ciona intestinalis in the field. Mar Ecol Prog Ser 259:139-144

Marshall DJ, Keough MJ (2003b) Sources of variation in larval size: maternal size and the local sperm environment. Invertebr Reprod Dev 44:63-70

Marshall DJ, Keough MJ (2003c) Variation in the dispersal potential of non-feeding invertebrate larvae: the desperate larva hypothesis and larval size. Mar Ecol Prog Ser 255:145-153

Marshall DJ, Pechenik JA, Keough MJ (2003a) Larval activity levels and delayed metamorphosis affect post-larval performance in the colonial ascidian Diplosoma listerianum. Mar Ecol Prog Ser 246:153-162

Marshall DJ, Bolton TF, Keough MJ (2003b) Offspring size affects the post-metamorphic performance of a colonial marine invertebrate. Ecology 84:3131-3137

McEdward LR, Coulter LK (1987) Egg volume and energetic content are not correlated among sibling offspring of starfish: implications for life-history theory. Evolution 41: 914-917

Moran AL, Emlet RB (2001) Offspring size and performance in variable environments: field studies on a marine snail. Ecology 82:1597-1612

Osman RW, Whitlatch RB (1995) Predation on early ontogenetic life stages and its effect on recruitment into a marine epifaunal community. Mar Ecol Prog Ser 117:111-126

Pechenik JA (1990) Delayed metamorphosis by larvae of benthic marine invertebrates: Does it occur? Is there a price to pay? Ophelia 32:63-94

Pechenik JA (1999) On the advantages and disadvantages of larval stages in benthic marine invertebrate life cycles. Mar Ecol Prog Ser 177:269-297

Pechenik JA, Hammer K, Weise C (1996) The effect of starva-

Editorial responsibility: Charles Peterson (Contributing

Editor), Morehead City, North Carolina, USA tion on acquisition of competence and post-metamorphic performance in the marine prosobranch gastropod Crepidula fornicata. J Exp Mar Biol Ecol 199:137-152

Pechenik JA, Wendt DE, Jarrett JN (1998) Metamorphosis is not a new beginning. Bioscience 48:901-910

Phillips NE (2002) Effects of nutrition-mediated larval condition on juvenile performance in a marine mussel. Ecology 83:2562-2574

Phillips NE, Gaines SD (2002) Spatial and temporal variability in size at settlement of intertidal mytilid mussels from around Pt. Conception, California. Invertebr Reprod Dev 41:1-3

Quinn GP, Keough MJ (2002) Experimental design and data analysis for biologists. Cambridge University Press, Melbourne

Sebens KP (1982) Competition for space: growth rate, reproductive output, and escape in size. Am Nat 120:189-197

Sebens KP (1987) The ecology of indeterminate growth in animals. Annu Rev Ecol Syst 18:371-401

Smith CC, Fretwell SD (1974) The optimal balance between size and number of offspring. Am Nat 108:499-506

Stearns SC (1992) The evolution of life histories. Oxford University Press, Oxford

Underwood AJ, Fairweather PG (1989) Supply side ecology and benthic marine assemblages. Trends Ecol Evol 4:16-21

Underwood AJ, Keough MJ (2001) Supply-side ecology-the nature and consequences of variations in recruitment of intertidal organisms. In: Bertness MD, Gaines SD, Hay ME (eds) Marine community ecology. Sinauer Associates, Sunderland, MA, p 183-200

Vaitilingon D, Morgan R, Grosjean P, Gosselin P, Jangoux, M (2001) Effects of delayed metamorphosis and food rations on the perimetamorphic events in the echinoid Paracentrotus lividus (Lamark, 1816) (Echinodermata). J Exp Mar Biol Ecol 262:41-60

Wendt DE (1996) Effect of larval swimming duration on success of metamorphosis and size of the ancestrular lophophore in Bugula neritina (Bryozoa). Biol Bull (Woods Hole) 191:224-233

Wendt DE (1998) Effect of larval swimming duration on growth and reproduction of Bugula neritina (Bryozoa) under field conditions. Biol Bull (Woods Hole) 195: 126-135

Wendt DE (2000) Energetics of larval swimming and metamorphosis in four species of Bugula (Bryozoa). Biol Bull (Woods Hole) 198:346-356

Submitted: January 5, 2004; Accepted: June 9, 2004 Proofs received from author(s): September 15, 2004 